\title{
Studies on Synthesis, Characterization, and Adsorption of Cationic Dyes from Aqueous Solutions Using Magnetic Composite Material from Natural Clay in Central Kalimantan, Indonesia
}

\author{
I Made Sadiana, Karelius*, Retno Agnestisia, Abdul Hadjranul Fatah \\ Universitas Palangka Raya, Education Chemistry, Palangka Raya, Indonesia \\ *email: iwanherman1@gmail.com
}

Received February 2, 2018; Accepted May 3, 2018; Available online May 31, 2018

\begin{abstract}
Clay is a natural material from crystalline silicate with layered structures, has high cation exchange capacity, and large surface area. These advantages can be used as an adsorbent for the removal of contaminants in aqueous solutions, such as heavy metals and dyes. In Indonesia, clays from Java, Sulawesi, and Sumatra islands have been used as adsorbent, furniture, and construction materials. Due to limited information about basic characteristics of clay from Kalimantan, this clay has not been utilized well. Therefore, natural clay from Kalimantan, especially in Central Kalimantan, was used as adsorbent of cationic dyes in this present study. However, the clay has difficulty for separating the solid phase from aqueous solution after adsorption process. To solve this problem, combining clay with magnetic material was opted. The objectives of this study are to synthesize the magnetic composite material from natural clay by coprecipitation method and to characterize the synthesized magnetic composite material using an x-ray diffraction method, transmission electron microscopy, and vibrating sample magnetometer. The adsorption properties of the synthesized magnetic composite material were evaluated using rhodamine B and methylene blue dyes in aqueous solution. Before magnetic composite material was synthesized, the clay was previously being activated for removing impurities. The magnetic material formed in the structure of clay had magnetite with particle size of $2.75 \mathrm{~nm}$ and the magnetization value of $24.91 \mathrm{emu} / \mathrm{g}$. The adsorption capacities of natural clay, activated clay, and magnetic composite of clay in rhodamine B were $34.29,76.27$, and $81.46 \mathrm{mg} / \mathrm{g}$, respectively, while in methylene blue were $30.25,83.92$, and $133.90 \mathrm{mg} / \mathrm{g}$, respectively. These results suggested that magnetic composite of clay can increase the adsorption capacities against dyes and accelerate the separation of the adsorbent solid phase from aqueous solution with largest adsorption capacity on methylene blue dye.
\end{abstract}

Keywords: clay, magnetic composite, coprecipitation, adsorption, and cationic dye.

\section{INTRODUCTION}

Clay is a natural material from crystalline silicate with layered structures. Clay has particle size less than $2 \mu \mathrm{m}$ (Ortega, Ramos, \& Flores-Cano, 2013). After Java and Sumatra, huge natural clay reserves $\left(8.9\right.$ million $\left.\mathrm{m}^{3}\right)$ were obtained in Central Kalimantan, Indonesia (Amarullah et al., 2002). The clay has high cation exchange capacity, large surface area, and structural stability (Ortega et al., 2013). These characteristics can be applied as adsorbent for removing contaminants in aqueous solutions, such as $\mathrm{Cd}(\mathrm{II})-\mathrm{Ni}$ (II) (Ortega et al., 2013), Cu(II) and Zn(II) (Musso, Parolo, Pettinari, \& Francisca, 2014), Cr(VI) (Zhao, Qi, Chena, \& Zhang, 2015), Pb(II) (Georgescu, Nardou, Zichil, \& Nistor, 2017), uranium (Gładysz-Płaska, Grabias, \& Majdan, 2017), phosphate ions (Sinta, Suarya, \& Santi, 2015), ammonium ions (Alshameri, He, Zhu, $\mathrm{Xi}, \&$ Tao, 2017), essential oils (Nakhli et al., 2018), basic red 46 and direct blue 85 (Santos \& Boaventura, 2016), and methylene blue, crystal violet, and congo red (Bentahar, Dbik, El Khomri, El Messaoudi, \& Lacherai, 2017). The results showed that the clay has good ability to remove those contaminants, although the adsorption capacities were higher in dyes than others.

For better adsorption, the clay should have large surface area that can be achieved by activation i.e. chemical and physical activations. The chemical activation is conducted using an acid solution, while calcination $\left(500^{\circ} \mathrm{C}\right)$ is applied for physical activation (Koyuncu, 2007). Application of clay as adsorbent has drawback i.e. difficult to seperate the solid phase from aqueous solution after adsorption process. To solve this problem, combining the clay with magnetic material could be opted. The magnetic property that is produced by magnetic material was needed to facilitate the separation process between the clay and liquid phase using an external magnetic field after the adsorption process (Cottet, Almeida, Naidek, Viante, \& 
Debacher, 2014; Chen, Zhou, Fiore, Tong, \& $\mathrm{Yu}, 2016)$. As a type of magnetic material, iron oxide $\left(\mathrm{Fe}_{3} \mathrm{O}_{4}\right)$ can be composed in the clay (Chen et al., 2016). It forms a ferromagnetic regularity with the highest magnetization saturation (Ms) value was $92 \mathrm{emu} / \mathrm{g}$ (Cullity, 1972). The synthesizing of magnetic composite material can be conducted by coprecipitation methods (Lee, Jeoung, Shin, Kim, \& Kim, 2004; Wu et al., 2012; Liu, Chen, Liu, Liu, \& Dong, 2014; Chang et al., 2016).

Rhodamine $\mathrm{B}$ and methylene blue are widely used in the textile industry. These compounds are cationic dyes. In the dyeing process, only $5 \%$ of dyes are used, the rest 95\% will be discharged in water as a waste (Purwamargapratala, Yusuf, \& Ridwan, 2013). These dyes are toxic and nondegradable, thus inapproppiate waste management will result negative impacts to environment and human health (Purwamargapratala., 2013). Based on these considerations, studies on synthesis, characterization, and adsorption of cationic dyes using magnetic composite material from natural clay in Central Kalimantan, Indonesia were conducted. This research was expected to increase the added value of natural clay and to decrease dye pollutions.

\section{MATERIAL AND METHODS}

\section{Materials}

The natural clay was obtained from Central Kalimantan, Indonesia. Rhodamine B (C.I no. 45170; C.I. name, basic violet 10; $\mathrm{C}_{28} \mathrm{H}_{31} \mathrm{ClN}_{2} \mathrm{O}_{3} ; 479.02 \mathrm{~g} / \mathrm{mol}$ ), and methylene blue (C.I no. 61734; C.I. name, Basic blue 9; $\mathrm{C}_{16} \mathrm{H}_{18} \mathrm{ClN}_{3} \mathrm{~S} ; 319.851 \mathrm{~g} / \mathrm{mol}$ ) were purchased from Malang, Indonesia. Analytical grade $\mathrm{FeCl}_{3} \cdot 6 \mathrm{H}_{2} \mathrm{O}, \mathrm{FeSO}_{4} \cdot 7 \mathrm{H}_{2} \mathrm{O}, \mathrm{NH}_{4} \mathrm{OH}, \mathrm{AgNO}_{3}$, $\mathrm{HCl}$, and $\mathrm{NaOH}$ were obtained from Merck, Tbk. All solutions were prepared using distilled water.

\section{Preparation of natural clay}

The natural clay was cleaned from rough impurities and then heated using an oven at $70^{\circ} \mathrm{C}$ for 3 hours. In addition, the clay was crushed and filtered with a $60 \mu \mathrm{m}$ nylon mesh. The natural clay was characterized using an $\mathrm{x}$ ray diffraction (XRD) method.

\section{Activation of natural clay}

Fifty grams of native clay were refluxed with $250 \mathrm{~mL}$ of $\mathrm{HCl} 3 \mathrm{M}$ for 3 hours at $100^{\circ} \mathrm{C}$. The clay was filtered and washed with distilled water, and then chlorine tested using $\mathrm{AgNO}_{3}$. The solid of clay was dried at $100{ }^{\circ} \mathrm{C}$ for 3 hours. After drying, the clay was crushed and filtered with a $60 \mu \mathrm{m}$ nylon mesh. In addition, this clay was calcined using furnace at $500{ }^{\circ} \mathrm{C}$ for 3 hours. The activated clay was characterized using the XRD method.

\section{Synthesis of magnetic composite material}

The coprecipitation method was used to synthesize the magnetic composite material. Firstly, $\mathrm{FeSO}_{4} .7 \mathrm{H}_{2} \mathrm{O}$ and $\mathrm{FeCl}_{3} .6 \mathrm{H}_{2} \mathrm{O}$ solutions were prepared in $100 \mathrm{~mL}$ with concentrations of $0.025 \mathrm{M}$ and $0.050 \mathrm{M}$, respectively. The two solutions were mixed with 2 grams of activated clay, and then were stirred at $85{ }^{\circ} \mathrm{C}$, while $\mathrm{NH}_{4} \mathrm{OH}$ solution was also added to achieve stable $\mathrm{pH}$ at 10 . This suspension was air-dried for 3 hours. Finally, the magnetic composite materials could be seperated using an external magnetic field. This composite material was washed with distilled water and dried for 2 hours at $110{ }^{\circ} \mathrm{C}$. Furthermore, the composite was crushed and filtered with a $60 \mu \mathrm{m}$ nylon mesh. The XRD method, transmission electron microscopy (TEM), and vibrating sample magnetometer (VSM), were used to characterize the composite material.

\section{Adsorption test}

Natural, activated, and magnetic composite clays were used to adsorb the 10 , $20,30,40$, and $50 \mathrm{ppm}$ of rhodamine $\mathrm{B}$ and methylene blue solutions at both $\mathrm{pH}$ of 2 and 4 . The use of 2 and $4 \mathrm{pH}$ was considered based on the optimum condition adsoption as obtained in the previous research (data is not shown). The processes were conducted using a shaker at room temperature for 3 hours. Concentration of rhodamine B and methylene blue in aqueous solution were measured using a UV-Vis spectrophotometer.

\section{Separation test}

The adsorbents of activated clay and magnetic composite material were added to rhodamine B and methylene blue solutions. These suspensions were then shaken at room temperature for $60 \mathrm{~min}$. Finally, from these suspensions, the adsorbents were seperated using an external magnetic field.

\section{RESULTS AND DISCUSSION}

Synthesis and characterization of magnetic composite material 
The synthesize of magnetic composite materials from natural clay was conducted with $\mathrm{Fe}^{2+}$ and $\mathrm{Fe}^{3+}$ solutions at mole ratio of $1: 2$ and $85^{\circ} \mathrm{C}$. These $\mathrm{Fe}^{2+}$ and $\mathrm{Fe}^{3+}$ ions entered into the structure of clay by ion exchange processes. In addition, $\mathrm{Fe}^{2+}$ and $\mathrm{Fe}^{3+}$ ions within structure of clay formed $\mathrm{Fe}(\mathrm{OH})_{2}$ and $\mathrm{Fe}(\mathrm{OH})_{3}$ due to the addition of $\mathrm{NH}_{4} \mathrm{OH}$ solution. $\mathrm{Fe}(\mathrm{OH})_{2}$ and $\mathrm{Fe}(\mathrm{OH})_{3}$ were oxidized and became magnetite $\left(\mathrm{Fe}_{3} \mathrm{O}_{4}\right)$ particles in the structure of clay. The natural, activated, and magnetic composite material clays were verified using an XRD instrument. The $\mathrm{x}$-ray difractogram for natural clay, activated clay and magnetic composite material clay are shown in Figure 1.
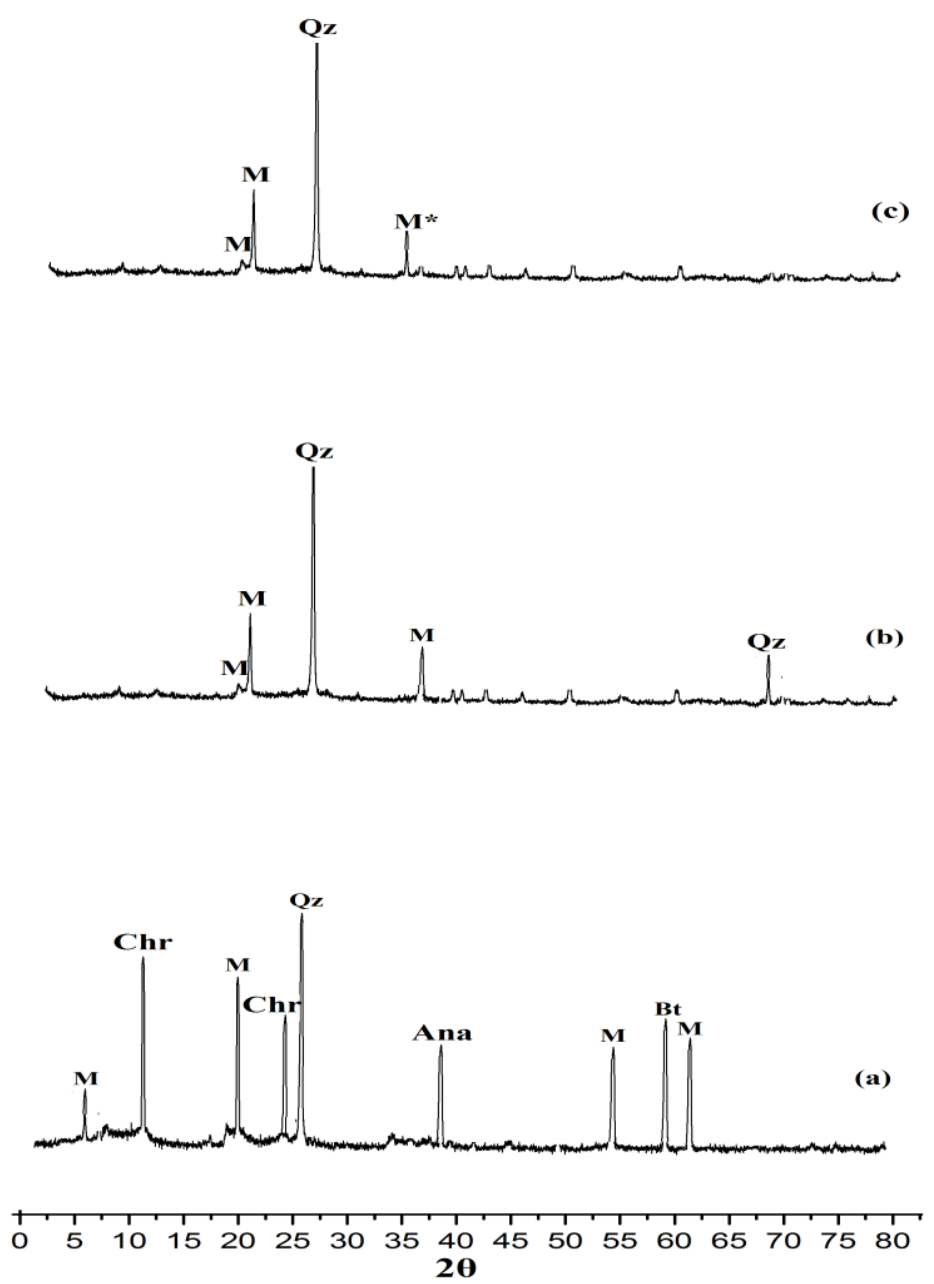

Figure 1. Difractogram of natural clay (a), activated clay (b), and magnetic composite material (c) $\left(\mathrm{M}=\right.$ monmorilonite, $\mathrm{Chr}=$ chrysotile, $\mathrm{Qz}=$ quartz, $\mathrm{Olg}=$ oligoclase, $\mathrm{Bt}=$ biotite, $\mathrm{M}^{*}=$ magnetite).

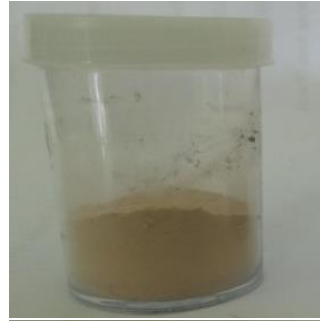

a

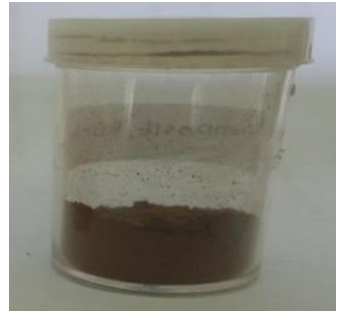

b

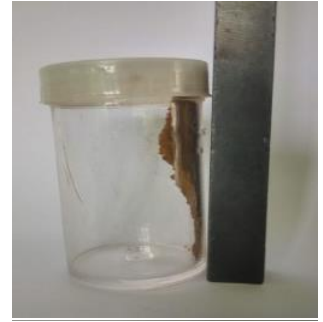

c

Figure 2. Activated of clay (a), magnetic composite (b) and magnetic composite with external magnetic field (c) 
Based on the Joint Comitte on Powder Difraction (JCPDS) standard, showing that the natural clay contained minerals of monmorilonite

$\left(\left(\mathrm{Si}_{7,8} \mathrm{Al}_{0,2}\right)^{\mathrm{IV}}\left(\mathrm{Al}_{3,4} \mathrm{Mg}_{0,6}\right)^{\mathrm{VI}} \mathrm{O}_{20}(\mathrm{OH})_{4}\right)$, chrysotile $\left(\mathrm{Mg}_{3} \mathrm{Si}_{2} \mathrm{O}_{5}(\mathrm{OH})_{4}\right)$, kuarsa $\left(\mathrm{SiO}_{2}\right)$, anatase $\left(\mathrm{TiO}_{2}\right)$, and biotite $\left.\left(\mathrm{K}(\mathrm{Mg}, \mathrm{Fe})_{3}(\mathrm{Al}, \mathrm{Fe}) \mathrm{Si}_{3} \mathrm{O}_{10}(\mathrm{OH}, \mathrm{F})_{2}\right)\right)$. The difractogram in Figure 1(a) and 1(b) showed that the peaks of chrysotile, anatase, and biotite in the clay disappeared after the activation processes. These results suggest that activation could remove impurity minerals, such as crysotile, oligoclase, and biotite. In Figure 2(c), the diffractogram also showed a change in the diffraction patterns of the magnetic composite material with showing a new peak at $35.35^{\circ}$. This peak showed magnetite $\left(\mathrm{Fe}_{3} \mathrm{O}_{4}\right)$ particles, which also were indicated by blackish colored of magnetic composite material as shown in Fig. 2b.

Figure 2(c) showed that the magnetic composite material had magnetic property because it was attached to an external magnetic field. This magnetic property was needed to facilitate the separation process between the clay and liquid phase after the adsorption process. The magnetization value of the composite material also is investigated using the VSM instrument. The result was presented as the hysteresis curve (Figure 3). The formed magnetic composite material was superparamagnetic with a magnetization value at $24.91 \mathrm{emu} / \mathrm{g}$.

The micro structural image of magnetic composite material was presented in Fig. 4. Figure 4 showed that magnetic composite material has a similar size and morphology. The particle image of the TEM is then measured with the J image software. The result show that the synthesize of magnetic composite material using the coprecipitation method produced about $2.75 \mathrm{~nm}$ of particle size. Smaller particle size would produce larger surface areas that benefit to increase the adsorption capacities of cationic dyes.

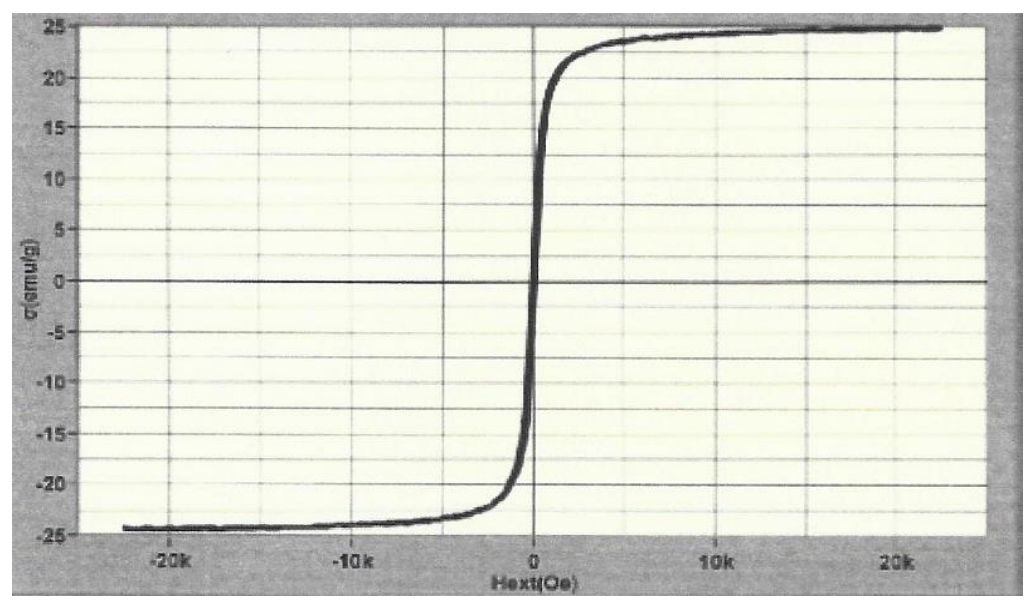

Figure 3. Hysteresis curve of magnetic composite

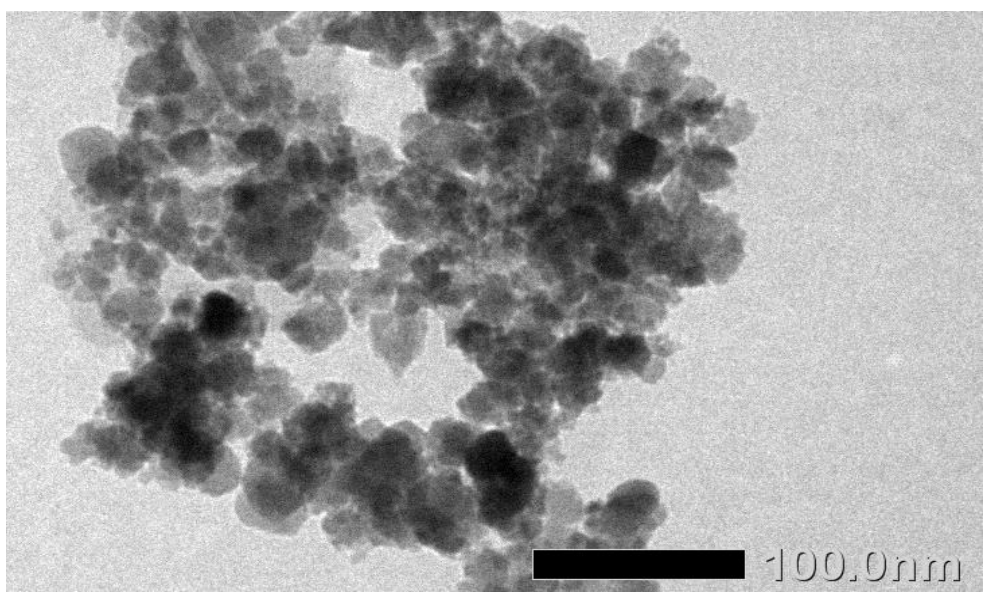

Figure 4. TEM Image of magnetic composite 


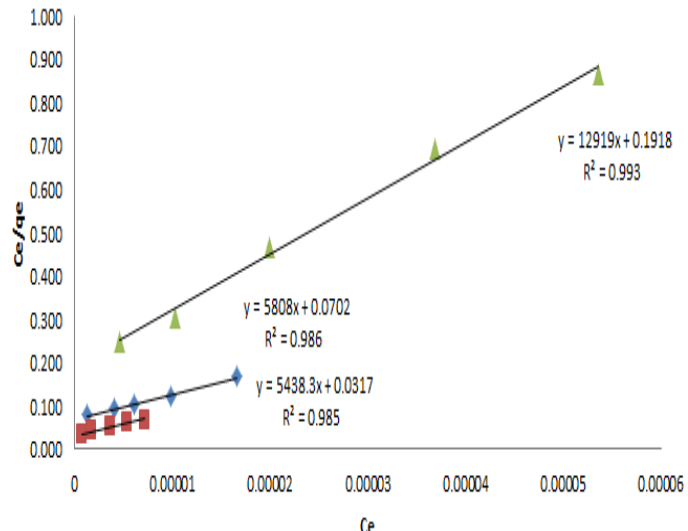

(a)

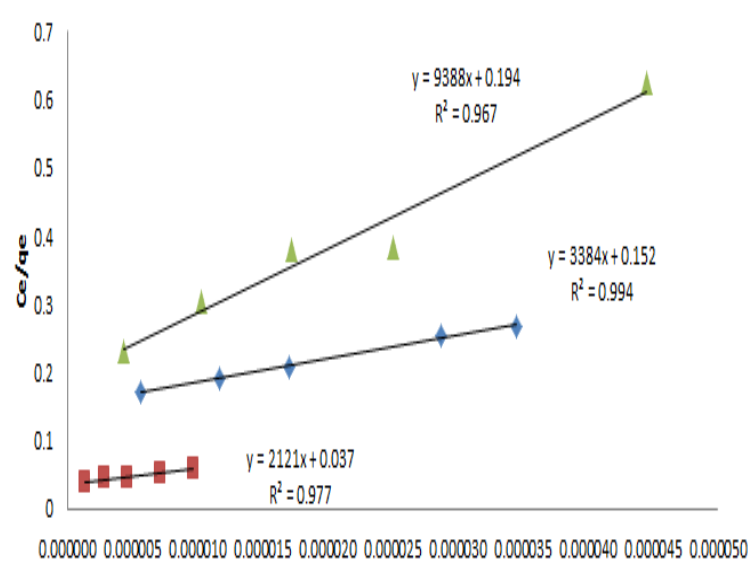

ce

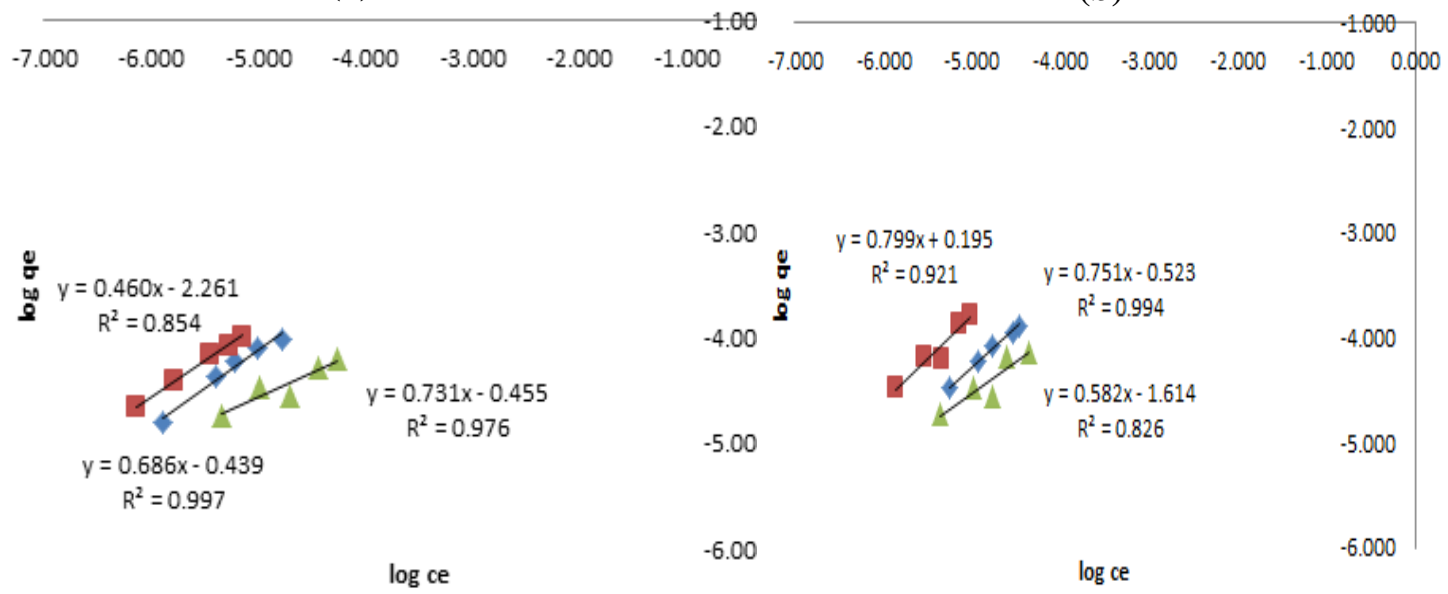

(c)

(d)

- Activated clay

\section{Magnetic composite}

Figure 5. Curves of Langmuir isotherm on rhodamine B (a), Langmuir isotherm on methylene blue (b), Freundlich isotherm on rhodamine B (c), and Freundlich isotherm on methylene blue (d)

\section{Mechanisms, capacity, and energy adsorptions for two cationic dyes \\ The clay contained mineral of} monmorilonite. This mineral has active site that can be used to adsorb the cationic dyes, such as rhodamine B and methylene blue (Bentahar et al., 2017). The results of adsorption in this study were tested using Langmuir and Freundlich isotherm models to determine the mechanisms of adsorption, adsorption capacity, and adsorption energy of adsorbents on rhodamine B and methylene blue dyes. Based on the linear regression value, the active sites in the adsorbents were homogeneous, indicating that a molecule of rhodamine B and methylene blue would attach to each an active site. The obtained higher correlation coefficients for the Langmuir model predicted that the range of rhodamine $B$ and methylene blue molecules were monolayer with mechanism of chemical adsorption. The Langmuir isotherm pattern can also determine the value of adsorption capacity (B) of the adsorbents as shown in Tables $\mathbf{1}$ and $\mathbf{2}$.

The adsorption capacities of natural clay, activated clay, and magnetic composite of clay for rhodamine B were $34.29,76.27$, and 81.46 $\mathrm{mg} / \mathrm{g}$, respectively (Table 1), while for methylene blue were $30.25,83.92$, and 133.90 $\mathrm{mg} / \mathrm{g}$, respectively (Table 2). These results showed that natural clay from Central Kalimantan can adsorb rhodamine $\mathrm{B}$ and methylene blue dyes and also can increase the adsorption capacities of activated and composited clays (Tables $\mathbf{1}$ and 2). These results were obtained because the clay contained mineral of monmorilonite. This mineral has permanently active site and it is negatively charged. This negative charge is formed from isomorphic substitution from monmorillonite. The negative charge referred 
as the active site of clay which can be used as an adsorbent to adsorb the cationic dyes, such as rhodamine $\mathrm{B}$ and methylene blue by electrostatic force (Bentahar et al., 2017) In

The addition of magnetite particles into the clay structure also can increase the adsorption capacities. The inclusion of magnetite particles into the interlayer of monmorillonite mineral of clay would form a two-dimensional porous material with a large surface area. The formed oxides between the layers are permanent and functioned as buffers between the layers (Hutson, Hoekstra, \& Yang, 1999), thus it allows rhodamine $B$ and methylene blue molecules to enter to the interlayer spaces and are bonded on the active sites of monmorillonite minerals of clay. The adsorption also can occur due to electrostatic force between oxygen atoms from magnetite that have a negative-partial charge with the positive-partial charge from rhodamine $B$ and addition, the activation process was also able to dissolve the impurities and open the hidden site, so that can increase the active site of clay (Trabelsi \& Tlili, 2017).

methylene blue molecules. Another possibility would be a coordinate covalent bond between magnetite and molecules dye. The oxygen atoms of magnetite have free electrons pairs that can be donated to group $=\mathrm{N}_{1}^{+}$of dyes that have an empty orbital, and then these pairs of electron are used together to form a coordinate covalent bond.

The data in Tables $\mathbf{1}$ and $\mathbf{2}$ also showed that methylene blue molecules were mostly adsorbed in the activated clay and magnetic composite material. This result was caused by the smaller molecular size of methylene blue than that of rhodamine B (Figure 6). The smaller molecular sizes would result in more easily bind to the active sites of adsorbents.

Table 1. Constant values of isotherm adsorption for rhodamine B

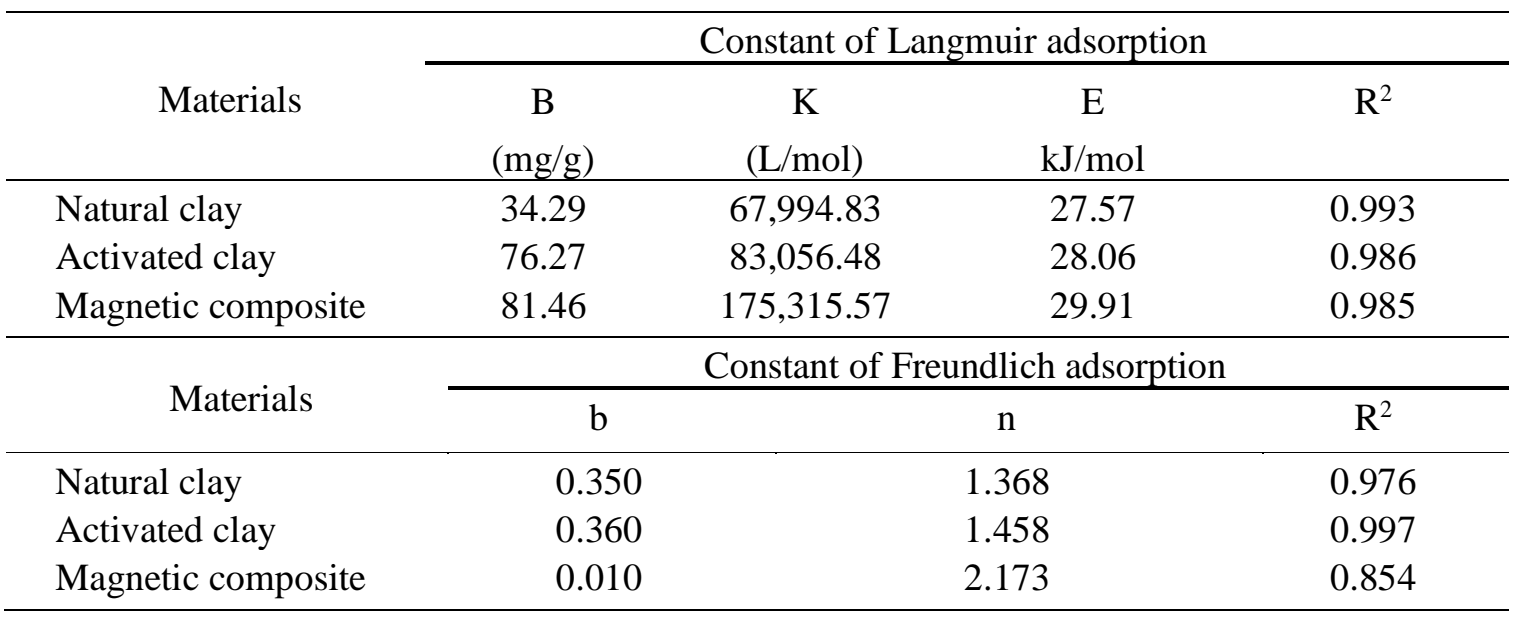

Table 2. Constant of isotherm adsorption for methylene blue

\begin{tabular}{|c|c|c|c|c|}
\hline \multirow[b]{2}{*}{ Materials } & \multicolumn{4}{|c|}{ Constanta of langmuir adsorption } \\
\hline & $\begin{array}{c}\text { B } \\
(\mathrm{mg} / \mathrm{g})\end{array}$ & $\begin{array}{c}\mathrm{K} \\
(\mathrm{L} / \mathrm{mol})\end{array}$ & $\begin{array}{c}\mathrm{E} \\
\mathrm{kJ} / \mathrm{mol}\end{array}$ & $\mathrm{R}^{2}$ \\
\hline Natural clay & 30.25 & $18,110.53$ & 24.29 & 0.967 \\
\hline Activated clay & 83.92 & $22,301.52$ & 24.80 & 0.994 \\
\hline Magnetic composite & 133.90 & $57,382.22$ & 27.15 & 0.977 \\
\hline \multirow[b]{2}{*}{ Materials } & \multicolumn{4}{|c|}{ Constant of Freundlich adsorption } \\
\hline & $\mathrm{b}$ & & $\mathrm{n}$ & $\mathrm{R}^{2}$ \\
\hline Native clay & 0.020 & & 1.718 & 0.826 \\
\hline Activated clay & 0.300 & & 1.332 & 0.994 \\
\hline Magnetic composite & 1.570 & & 1.232 & 0.921 \\
\hline
\end{tabular}


The application of the Langmuir isotherm equation can be developed to determine the adsorption energy, according to the equation of $\mathrm{E}=\mathrm{RT} \ln \mathrm{K}$. Based on calculation using this equation, the values of adsorption energy for rhodamine $B$ and methylene blue in the three types of adsorbent exceeded $20 \mathrm{~kJ} / \mathrm{mol}$ (as shown in Tables $\mathbf{1}$ and 2). These results suggest that the bonds between the active sites of adsorbent with cationic dyes are chemical bonding. The adsorption between the clay and dyes occurs by the electrostatic forces. While, the adsorption between the magnetic composite of clay and dyes occurs by electrostatic forces and coordinate covalent bond.<smiles></smiles>

(a)
Separation test of adsorbents in dye solutions

The activated clay and magnetic composite of clay were used in this study to investigate separation test. After these adsorbents were used in the adsorption processes, they were separated from the aqueous solutions. The activated clay adsorbent was separated by sedimentation using force of gravity, while an external magnetic field was used to seperate the magnetic composite material adsorbent from the solutions (Figure 7).

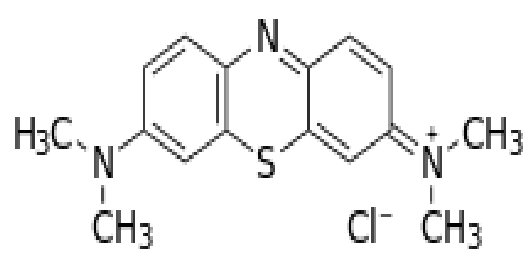

(b)

Figure 6. Structural molecule of rhodamine B (a) and methylene blue (b)

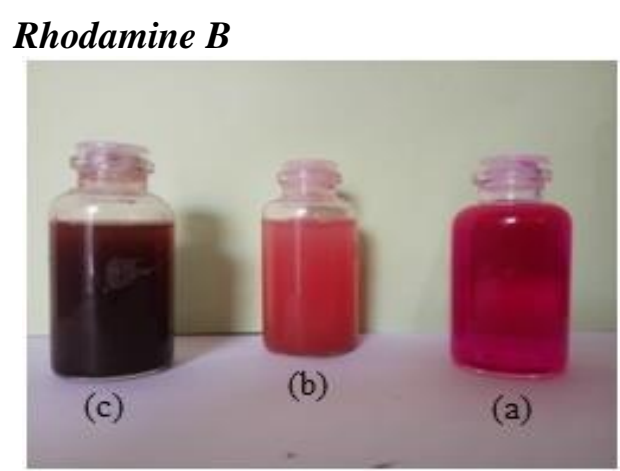

Initial solution

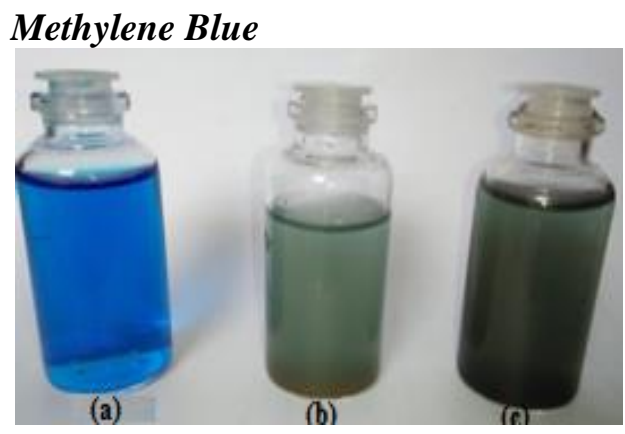

Initial solution

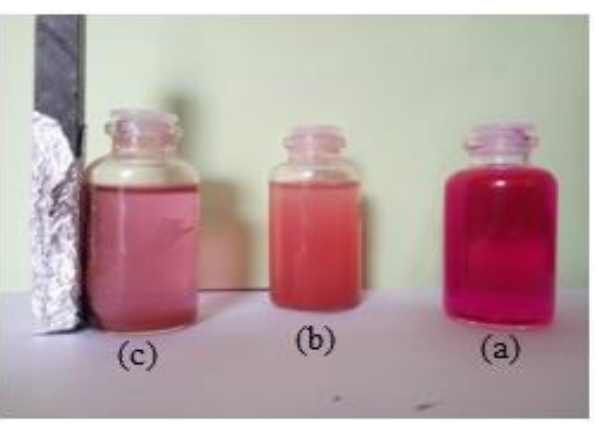

Solution after 5 minutes

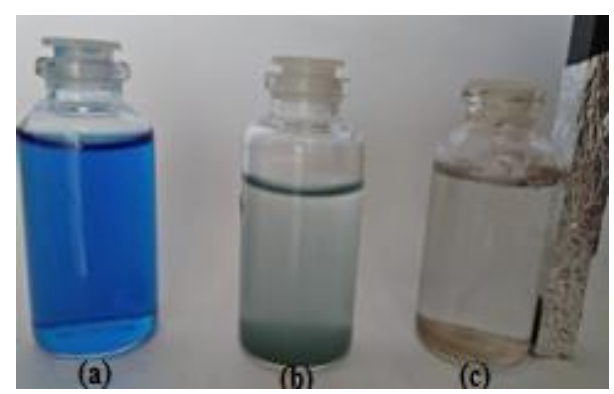

Solution after 5 minutes

Figure 7. Separation test of adsorbents on dye solution; Initial dye solution (a), dye solution after adsorption with activated clay (b) and dye solution after adsorption with magnetic composite (c). 


\section{CONCLUSION}

The magnetic material formed in the structure of clay had magnetite with the magnetization value of $24.91 \mathrm{emu} / \mathrm{g}$. The adsorption capacities of natural clay, activated clay, and magnetic composite of clay in rhodamine B were 34.29 , 76.27 , and $81.46 \mathrm{mg} / \mathrm{g}$, respectively, while in methylene blue were $30.25,83.92$, and 133.90 $\mathrm{mg} / \mathrm{g}$, respectively. These results suggested that magnetic composite of clay can increase the adsorption capacities against dyes and accelerate the separation of the adsorbent solid phase from aqueous solution with largest adsorption capacity on methylene blue dye.

\section{ACKNOWLEDGEMENT}

The authors were grateful for financial support from DRPM DIKTI through the Grant of Applied Products in 2017.

\section{REFERENCES}

Amarullah, D., Margani, U., Saksono, Priatna, Priono, \& Sudiro. (2002). Inventarisasi dan evaluasi endapan batubara kabupaten Barito Selatan dan Barito Utara Provinsi Kalimantan Tengah. Kolokium Direktorat Inventarisasi Sumber Daya Mineral, (DIM) TA, 20, 114.

Alshameri, A., He, H., Zhu, J., Xi, Y., \& Tao, Q. (2017). Adsorption of ammonium by different natural clays minerals: Characterization, kinetics and adsorption isotherms. Applied Clay Science. In press, corrected proof.

Bentahar, S., Dbik, A., El Khomri, A., El Messaoudi, N., \& Lacherai, A. (2017). Adsorption of methylene blue, crystal violet and congo red from binary and ternary systems with natural clay. Kinetic, isotherm, and thermodynamic. Journal of Environmental Chemical Engineering, 5, 5921-5932.

Chang, J. L., Ma, J. L., Zang, D. D., Qiao, N. N., Hu, M. X., \& Ma, H. J. (2016). Adsorption of methylene blue onto Fe3O4/activated montmorillonite nanocomposite. Applied Clay Science, 119, 132-140.Chen, L., Zhou, C, H., Fiore, S., Tong, D, S., \& Yu, W, H. (2016). Functional magnetic nanoparticle/clay mineral nanocomposites: preparation, magnetism and versatile applications. Applied Clay Science, 127-128, 143-163.

Cottet, L., Almeida, N. Naidek, M.F. Viante, \& Debacher. (2014). Adsorption characteristics of montmorillonite clay modified with iron oxide with respect to methylene blue in aqueous media. Applied Clay Science, 95, 25-31.

Cullity, B. D. (1972). Introduction to Magnetic Materials. London: Addison Esley Publishing Company.

Georgescu, A., Nardou, F., Zichil, V., \& Nistor. I. (2018). Adsorption of lead(II) ions from aqueous solutions onto Cr-pillared clays. Applied Clay Science, 152, 44-50.

Gładysz-Płaska, A., Grabias, E., \& Majdan, M. (2017). Simultaneous adsorption of uranium(VI) and phosphate on red clay. Progress in Nuclear Energy. In press, corrected proof.

Hutson, N. D., Hoekstra, M. J., \& Yang, R. T. (1999). Control of microporosity of Al2O3-pillared clays: effect of $\mathrm{pH}$, calcination temperature and clay cation exchange capacity. Microporous and Mesoporous Materials, 28, 447- 459.

Koyuncu, H. (2007) Adsorption kinetics of 3hydroxybenzaldehyde on native and activated bentonite. Applied Clay Science, 38, 279-287.

Lee, S. J., Jeoung, J. R., Shin, S.C., Kim, J. C \& Kim, J. D. (2004). Synthesis and characterization of superparamagnetic magnetite nanoparticles prepared by Coprecipitation Technique. Magnetism, Magnetic Mater, 282, 147-150.

Liu, H. C., Chen, W., Liu, C., Liu, Y., \& Dong, C. L. (2012). Magnetic mesoporous clay adsorbent: preparation, characterization and adsorption capacity for atrazine. Microporous and mesoporous, 194, 7278.

Musso, Parolo, Pettinari \& Francisca, F. (2014). $\mathrm{Cu}$ (II) And $\mathrm{Zn}$ (II) adsorption capacity of three different clay liner materials. Journal of Environmental Management, $146,50-58$.

Nakhli, A., Goletti, M., Mbouga, M., Bergaoui, M., Khalfaoui, M., \& Huguet, P. (2018). Modeling of essential oils adsorption onto clay towards a better understanding of their interactions. Journal of Molecular Liquids, 249, 132-143. 
Studies on Synthesis, Characterization, and Adsorption of Cationic Dyes I Made Sadiana, et. al.

Ortega, E., Ramos \& Flores-Cano. (2013). Binary adsorption of heavy metals from aqueous solution onto natural clays. Chemical Engineering Journal, 225, 535-546.

Purwamargapratala, Y., Yusuf, S \& Ridwan. (2013). Degradasi metilen biru dengan komposit $\mathrm{TiO} 2 \mathrm{SiO} 2 \mathrm{Fe} 3 \mathrm{O} 4$. Prosiding Seminar Nasional IX SDM Teknologi Nuklir. Yogyakarta, Indonesia: ISSN 1978-0176.

Santos, R., \& Boaventura. (2016). Adsorption of cationic and anionic azo dyes on sepiolite clay: Equilibrium and kinetic studies in batch mode. Journal of Environmental Chemical Engineering, 4, 1473-1483.

Sinta, I, N., Suarya, P, \& Santi. (2015). Adsorpsi ion fosfat oleh lempung teraktivasi asam sulfat (H2SO4). Jurnal Kimia, 2, 217-225.

Trabelsi, W., \& Tlili, A. (2017). Phosphoric acid purification through different raw and activated clay materials (Southern Tunisia). Journal of African Earth Sciences, 129, 647-658.

Wu, D., Zhu, C., Chen, Y., Zhu, B., Yang, Y., Wang, Q., \& Ye, W. (2012). Preparation, characterization and adsorptive study of rare earth ions using magnetic GMZ bentonite. Applied Clay Science, 62, 8793.

Zhao, Y., Qi, Chena, Q., \& Zhang. (2015). Behavior of $\mathrm{Cr}(\mathrm{VI})$ removal from wastewater by adsorption onto $\mathrm{HCl}$ activated Akadama clay. Journal of the Taiwan Institute of Chemical Engineers, 50, 190-197. 